\title{
IN VITRO STUDY OF A TRANSFERSOMAL GEL PREPARATION CONTAINING LYNESTRENOL AS A TRANSDERMAL DRUG DELIVERY SYSTEM
}

\author{
NURFITRIYANA NURFITRIYANA, HARMITA HARMITA, ISKANDARSYAH ISKANDARSYAH*
}

Department of Pharmacy, Physical Pharmacy Laboratory, Faculty of Pharmacy, Universitas, Indonesia. Email: aya_2803@yahoo.com

Received: 26 September 2019, Revised and Accepted: 17 December 2019

ABSTRACT

Objective: Lynestrenol, a progestin hormone derivative, can suppress the productions of endogenous estrogen and progesterone hormones (ovaries) to prevent ovulation. In this study, lynestrenol was included in various transfersomal gel preparations for its transdermal delivery into fat (F)-and non-fat (NF)-containing skin tissues.

Methods: Lynestrenol transfersome vesicles were prepared by encapsulating the drug in varied concentrations of phosphatidylcholine and Tween 80 using lipid film hydration method. Transfersomes were produced in the form of gel preparations at a dose of 0.15 mg/week and evaluated for their particle size, percentage of entrapment efficiency, and particle polydispersity. We performed in vitro evaluations of the formulation variants F0 (lynestrenol gel control) and F1 and F2 (lynestrenol transfersome gels) with variations in their phosphatidylcholine and Tween 80 content. We then performed an in vitro evaluation using the Franz diffusion cell (FDC) method for $12 \mathrm{~h}$ using all three formulations on F and NF-containing rat skin.

Results: The FDC results demonstrated that lynestrenol was deposited into fat tissue and increased concentrations of Tween 80 (edge activator) increased lynestrenol delivery into this tissue. In addition, the percentages of drug penetration from NF rat skin treated with F0, F1, and F2 gels were $19.56 \%, 20.13 \%$, and $20.56 \%$, respectively, and those from F rat skin were $17.16 \%, 17.38 \%$, and $17.50 \%$, respectively.

Conclusion: In vitro evaluation using the FDC method indicates that transdermal drug delivery through to fat tissues using transfersomes is a promising method for lynestrenol delivery.

Keywords: Transfersomes, Lynestrenol, Franz diffusion cell.

(C) 2020 The Authors. Published by Innovare Academic Sciences Pvt Ltd. This is an open access article under the CC BY license (http://creativecommons. org/licenses/by/4. 0/) DOI: http://dx.doi.org/10.22159/ijap.2020.v12s1.FF052

\section{INTRODUCTION}

Oral contraceptive tablets have been used for more than 50 years, but user self-discipline is required as they must be consumed regularly at the same times each day [1]. Transdermal drug delivery systems have a number of advantages over oral pills, as they provide continuous administration of drug through the skin, which maintains constant plasma drug levels and avoids the peaks and troughs that are seen with oral drug administration [2].

The use of a transdermal system for contraception presents a number of clinical advantages over the conventional oral method. A once-weekly administration of a drug is more convenient for women compared with a once-daily administration and should also improve the overall efficacy by decreasing the degree to which it is dependent on user action [3].

From a pharmacokinetic perspective, transdermal delivery of contraceptive hormones eliminates variability in gastrointestinal (GI) absorption, and factors such as stomach $\mathrm{pH}$, the stomach emptying rate, GI motility, and GI transit time [4]. The drug is delivered directly into the systemic circulation, which avoids hepatic first-pass metabolism and maintains constant circulating drug concentrations [5].

The fundamental challenge to transdermal drug delivery systems is crossing the barrier of the skin, which has a low permeability to foreign molecules due to the lipid-rich composition of the stratum corneum [6]. Solutes passing through the skin must move between cells and along the interfaces of extracellular lipid bilayers. As a result, sophisticated pharmacological and technical approaches are required to allow continuous drug delivery through the skin [7].

Lynestrenol is one of the hormones given by health workers to prospective reproductive patients [8]. It is able to effectively delay menstruation by inhibiting follicular maturation and preventing spikes in luteinizing hormone concentration so that the endometrium remains thin. The lynestrenol preparations that are currently available on the market are only in tablet form. A $0.5 \mathrm{mg}$ dose is taken twice daily from the $5^{\text {th }}$ day of the menstrual cycle. Orally administered lynestrenol undergoes first-pass metabolism, which results in $64 \%$ bioavailability of the drug compared with the amount consumed and a half-life of 5-6 h $[9,10]$. In this study, we examine the penetration of lynestrenol into the bloodstream using transdermal delivery to avoid the disadvantages of oral delivery.

\section{MATERIALS AND METHODS}

\section{Materials}

Lynestrenol was purchased from IPC (Pirumadara, India); Tween 80 and Phospholipon ${ }^{\circledR}$ 90G (Soya phosphatidylcholine $\geq 91 \%$ ) were purchased from lipoid $\mathrm{GmbH}$ (Ludwigshafen, Germany); potassium dihydrogen phosphate monohydrate, sodium hydroxide, and dichloromethane were purchased from Merck (Darmstadt, Germany); methylparaben, propylparaben, glycerine, and propylene glycol were purchased from Dow Chemical (Jakarta, Indonesia); and hydroxypropyl methylcellulose (HPMC) K4M, sodium metabisulfite, aquadest, and ethanol (96\%) were purchased from Merck (Darmstadt, Germany). Methanol and acetonitrile were of analytical grade and were purchased from Satya Darmawan (Jakarta, Indonesia).

\section{Methods}

Preparation of transfersomes

Vesicles were prepared using the thin-film hydration method. Different concentrations of the lipid Phospholipon ${ }^{\circledR}$ 90G (soya phosphatidylcholine) and the edge activator Tween 80 were employed for the formulation of the vesicles. The lipid, the edge activator, 
and the drug (lynestrenol) were accurately weighed and dissolved in dichloromethane. This solution was evaporated using a rotary evaporator (Buchi R-100, Flawil, Switzerland) at $40^{\circ} \mathrm{C}$ and $850 \mathrm{mbar}$ vacuum pressure. The thin film was maintained under a continuous flow of nitrogen and stored at $4^{\circ} \mathrm{C}$ for $24 \mathrm{~h}$. The thin film obtained was then hydrated with phosphate-buffered saline ( $\mathrm{pH}$ 7.4). The formulations used (with different concentrations of lipid and edge activator) are shown in Table $1[11,12]$.

Determination of particle sizes, zeta potentials, and polydispersity indexes (PDIs)

The particle sizes, zeta potentials, and PDIs were measured for the F1 and F2 transfersomes using the dynamic light scattering technique at $25^{\circ} \mathrm{C}$ using the particle size system, (Zetasizer, Malvern, UK; Beckman Coulter, USA). The transfersomal colloidal dispersion was diluted with purified water before analysis $[11,13]$.

Calculating the percentage of entrapment efficiency (EE\%) of lynestrenol in transfersomes

Aliquots $(1 \mathrm{ml})$ of the $\mathrm{F} 1$ and $\mathrm{F} 2$ transfersomes were separately centrifuged at $10,000 \mathrm{rpm}$ for $1 \mathrm{~h}$ at $4^{\circ} \mathrm{C}$ to allow the separation of the non-entrapped drug. Next, $1 \mathrm{ml}$ of $0.1 \%$ Triton X-100 was added and the mixture was centrifuged at $10,000 \mathrm{rpm}$ for $1 \mathrm{~h}$ at $4^{\circ} \mathrm{C}$ to allow the separation of the entrapped drug. The supernatant was collected and $10 \mathrm{ml}$ methanol was added. The mixture was analyzed chromatographically at $204 \mathrm{~nm}$ using a high-pressure liquid chromatography (HPLC) system (Shimadzu, Japan) $[11,13]$. The EE\% of lynestrenol in the prepared transfersomes was calculated by applying the following equation:

$$
\% \mathrm{EE}=\frac{\text { Total amount of drug }- \text { Amount of entrapped drug }}{\text { Total amount of drug }} \times 100
$$

Preparation of lynestrenol gel and lynestrenol transfersome gels In addition to gels prepared from of the F1 and F2 lynestrenol transfersomes, a control lynestrenol gel (F0) was also evaluated. Gels were formulated using 5\% (w/v) HPMC as a gelling agent and approximately $0.15 \mathrm{mg}$ of lynestrenol (F0) or $0.5 \mathrm{ml}$ lynestrenol transfersomes (F1 and F2). First, HPMC was dispersed in distilled water and then mixed with F0, F1, or F2 while stirring. A mixture of $0.2 \%$ $(\mathrm{w} / \mathrm{v})$ methylparaben, $0.1 \%(\mathrm{w} / \mathrm{v})$ propylparaben, $5 \%(\mathrm{w} / \mathrm{v})$ glycerine, $5 \%(\mathrm{w} / \mathrm{v})$ propylene glycol, and $0.01 \%(\mathrm{w} / \mathrm{v})$ sodium metabisulfite was subsequently added, and the mixture was stirred for $5 \mathrm{~min}$ at $500 \mathrm{rpm}$ to adjust the $\mathrm{pH}$ to $6-7$ and produce a proper gel consistency $[12,13]$.

\section{In vitro diffusion tests}

Permeation studies were performed using a Franz diffusion cell apparatus with a $16 \mathrm{ml}$ receptor compartment capacity and a diffusion area of $1.7 \mathrm{~cm}^{2}$. First, excised dorsal rat abdominal skin was mounted between the donor and receptor compartments of the diffusion cell with the stratum corneum layer facing into the donor compartment, while the dermis faced the receptor compartment. Phosphate-buffered saline ( $\mathrm{pH}$ 7.4) was used as the receptor solution for permeability studies of all the prepared formulations (which were performed at a temperature of $37^{\circ} \mathrm{C} \pm 2^{\circ} \mathrm{C}$ ) for $12 \mathrm{~h}$. Next, $0.5 \mathrm{~g}$ of gel prepared from each of the three formulations (F0, F1, and F2) were separately placed over fat-containing (F) and non-fat-containing (NF) areas of the stratum corneum facing the donor compartment. Samples $(2 \mathrm{ml})$ were withdrawn at different intervals $(1,2,3,4,5,6,8,10$, and $12 \mathrm{~h})$ and analyzed for drug content using HPLC analysis. All experiments were performed in triplicate and the mean values were calculated. The percentage cumulative penetration per square centimeter of gel was plotted against time for each formulation $[14,15]$.

\section{RESULTS AND DISCUSSION}

Particle sizes, zeta potentials, and PDIs

As shown in Table 2, the particle sizes of the F1 vesicles were smaller $(443.90 \mathrm{~nm})$ than the $\mathrm{F} 2$ vesicles $(558.10 \mathrm{~nm})$. This may be attributed
Table 1: Formulations of lynestrenol transfersomes

\begin{tabular}{lll}
\hline Ingredients & \multicolumn{2}{l}{ Concentration (\%) } \\
\cline { 2 - 3 } & $\begin{array}{l}\text { Formulation 1 } \\
\text { (F1) }\end{array}$ & $\begin{array}{l}\text { Formulation 2 } \\
\text { (F2) }\end{array}$ \\
\hline Lynestrenol & $300 \mathrm{mg}$ & $300 \mathrm{mg}$ \\
Phospholipon 90G & 9 & 8 \\
Tween 80 & 1 & 2 \\
Phosphate buffer (pH 7.4) & Add 50 ml & Add 50 ml \\
\hline
\end{tabular}

Table 2: Transfersome characterization

\begin{tabular}{lllll}
\hline Formulation & $\begin{array}{l}\text { \% Entrapment } \\
\text { efficiency }\end{array}$ & $\begin{array}{l}\text { Vesicle } \\
\text { size } \\
\text { (nm) }\end{array}$ & $\begin{array}{l}\text { Zeta } \\
\text { potential } \\
\text { (mV) }\end{array}$ & $\begin{array}{l}\text { Polydispersity } \\
\text { index }\end{array}$ \\
\hline F1 & 56.87 & 443.90 & -23.80 & 0.550 \\
F2 & 60.76 & 558.10 & -21.86 & 0.441 \\
\hline
\end{tabular}

to the fact that Tween 80 is a hydrophilic surfactant with a lower hydrophile-lipophile balance (HLB). Therefore, the transfersomes prepared with a small concentration of the surfactant Tween 80 (F1) have a smaller size compared with those prepared using a higher concentration (F2). The direct proportionality between vesicle size and the surfactant HLB can be explained by a reduction in surface free energy that takes place as a result of high hydrophobicity. The same explanation can be applied to the observation that a decrease in vesicle size occurs as the total lipid content increases.

As shown in Table 2, both of the formulations had negative zeta potential values: $-23.81 \mathrm{mv}$ for $\mathrm{F} 1$ and $-21.86 \mathrm{mv}$ for F2. It is highly likely that the negative zeta potential values of the transfersomes are largely due to the presence of ionic nitrogen atoms in the lynestrenol structure. The magnitudes of the zeta potentials in all the prepared formulations are sufficiently high to prevent their coagulation and to provide vesicle stability.

Size distribution is another highly important parameter that is expressed by a dimensionless value called the PDI. This parameter is a measure of particle homogeneity and varies from 0.0 to 1.0 . The closer the PDI value is to zero, the more homogenous the vesicles will be. All the formulations showed good uniformity in vesicle size, as the PDI of F1 and F2 was measured as 0.550 and 0.441 , respectively. This indicates that the vesicles were of a homogenous size and distribution, and suggested they were more uniform with a higher physical stability.

To summarize, two vesicle formulations (F1 and F2) with different concentrations of lipid (phospholipid) and edge activator (Tween 80 ) were investigated. Table 2 shows their measured particle sizes, zeta potentials, and PDIs. Our EE experiments indicated that the F2 formulation exhibited a higher EE (60.76\%) than the F1 formulation (56.87\%). F1 contained a greater concentration of soya phospholipid and a lower concentration of Tween 80 than F2. This suggests that the larger F2 particle size has more space for the entrapment of drugs.

\section{In vitro diffusion test and deposition}

The cumulative percentage of drug penetration into the receptor compartment fluid (transdermal amount) from the skin after $12 \mathrm{~h}$ of lynestrenol treatment using gels prepared using the formulations F0, F1, and F2 is presented in Fig. 1. These indicated that lynestrenol was deposited in the skin containing $\mathrm{F}$ than in that containing NF. A significantly higher lynestrenol penetration was obtained from the control lynestrenol gel (F0) than from the transfersomal lynestrenol gels (F1 and F2). The penetrated values of lynestrenol from NF skin were $19.56 \%, 20.13 \%$, and $20.56 \%$ for F0-, F1-, and F2-delivered lynestrenol, respectively, and $17.16 \%, 17.38$, and $17.50 \%$ for F0-, 


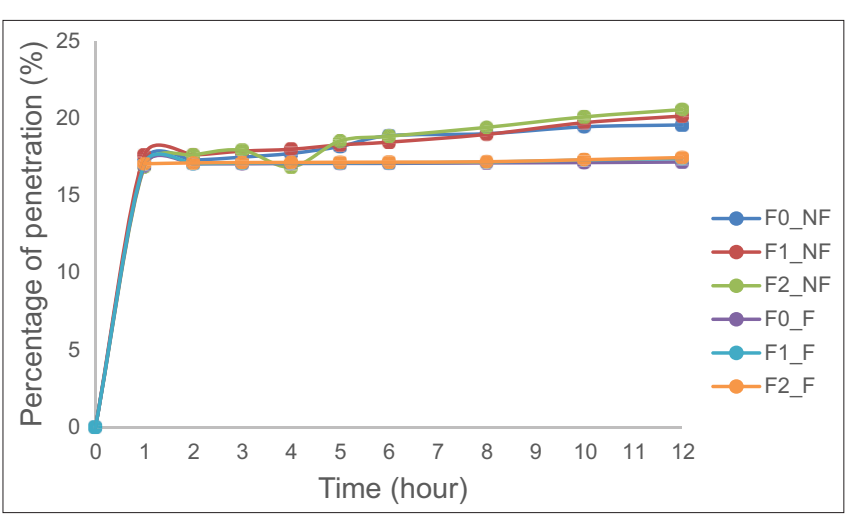

Fig. 1: Penetration profile of lynestrenol from formulations.

F0: Lynestrenol gel, F1: Gel prepared from lynestrenol-containing transfersomes of formulation 1, F2: Gel prepared from

lynestrenol-containing transfersomes of formulation 2. F: Rat skin with fat, NF: Rat skin without fat

F1-, and F2-delivered lynestrenol, respectively, from NF skin after a 12-h penetrated. The higher lynestrenol penetration from the transfersomal gels could be attributed to the nature due to these formulations because the drug was present in nanosized lipid vesicles.

Furthermore, the addition of different surfactant molecules (e.g., Span 80 ) in these formulations would facilitate the partitioning of the drug from the vesicles as they become associated with the phospholipid bilayer and therefore allow a higher drug penetrated from the vesicles.

We used different types of rat skin ( $\mathrm{F}$ and NF) to study the in vitro penetration of lynestrenol (Fig. 1). Lynestrenol was deposited into F skin, presumably because transfer some carriers are known to cause drug accumulation in fatty tissues. Studies with F-containing skin, as opposed to NF skin, showed less penetration of lynestrenol; this was the case for lynestrenol deposited in fatty tissues from all the gel formulations. The differing lynestrenol permeation observed between the F1 and F2 formulations through skin is highly likely to be a result of their varied concentrations of soya phospholipid and Tween 80 .

Increasing the concentration of Tween 80 (as in F2) increases the permeation of lynestrenols. Transfersomes containing Tween 80 have the structural flexibility to penetrate the skin and, as a result, the F2 formulation causes a higher lynestrenol penetration compared with F1.

Based on our in vitro results, lynestrenol can be deposited into fatcontaining skin through both our formulations of transfersomal gels to allow a controlled dose of lynestrenol of $1 \mathrm{mg} /$ day, over a single week (equivalent to 1 week of orally administered lynestrenol). The percentages of drug penetration from both the formulations $(17.16 \%$ to $17.50 \%$ from fat-containing skin) indicate that a proportion of the drug is penetrated in $12 \mathrm{~h}$ while the rest accumulates in the skin.

\section{CONCLUSION}

In this study, we developed transdermal lynestrenol delivery systems using transfersomes. In addition, we demonstrated their capability to go through the skin barrier to deliver the drug.

Our in vitro studies using three different formulations showed that lynestrenol accumulated in fat and a deposition drug level could be detected after a 12-h application of the drug. Furthermore, in vitro studies showed a lower percentage penetration of lynestrenol deposited in F skin compared with NF skin.

Finally, based on our results, we can conclude that the formulated lynestrenol transfersomal gels do have potential for the efficient transdermal delivery of lynestrenol as they enable a significantly higher amount of lynestrenol to be permeated through excised rat skin compared with control (non-transfersomal) lynestrenol gels, which is concomitant with a higher flux and permeability coefficient.

\section{ACKNOWLEDGMENT}

The authors gratefully acknowledge to Directorate of Research and Community Engagements of Universitas Indonesia for financial support: Hibah PITTA B number NKB:-0476/UN2.R3.1/HKP.05.00/2019.

\section{CONFLICTS OF INTEREST}

All authors have none to declare.

\section{REFERENCES}

1. Graziottin A. A review of transdermal hormonal contraception: Focus on the ethinylestradiol/norelgestromin contraceptive patch. Treat Endocrinol 2006;5:359-65.

2. Burkman RT. The transdermal contraceptive system. Am J Obstet Gynecol 2004;190:S49-53.

3. Smallwood GH, Meador ML, Lenihan JP, Shangold GA, Fisher AC, Creasy GW, et al. Efficacy and safety of a transdermal contraceptive system. Obstet Gynecol 2001;98:799-805.

4. Audet MC, Moreau M, Koltun WD. Evaluation of contraception efficacy and cycle control of transdermal contraceptive patch vs oral contraception. Int J Ginecolobstet 2001;70:78.

5. Archer DF, Bigrigg A, Smallwood GH, Shangold GA, Creasy GW, Fisher AC. Assessment of compliance with a weekly contraceptive patch (Ortho Evra/Evra) among North American women. Fertil Steril 2002;77:S27-31.

6. Reddy D. Transfersomea novel vascular carrier for transdermal drug delivery system. J Innov Pharm Biol Sci 2015;2:193-208.

7. Prajapati ST, Charmi GP, Chhagan N. Transfersomes: A vesicular carrier system for transdermal drug delivery. Asian J Biochem Pharm Res 2011;1:507-24.

8. Bazlad A, Wiweko B, Hendarto H. Tips for Managing Menstrual Patterns during Hajj and Umrah: Basic Mechanisms, Problems and Solutions [Kiatmengaturpolahaidsaat Haji Danumrah: Mekanismedasar, Masalahdansolusinya]. Jakarta: Himpunan Endokrinologi Reproduksidan Fertilitas; 2007.

9. Saman RR. FlightHealth in theHajj [Kesehatanpenerbangandalamibadah Haji]. Indonesia, Jakarta: Badan Penerbit Fakultas Kedokteran Universitas; 2011

10. Yasuda J, Honjo H, Okada H. Metabolism of lynestrenol: Characterization of 3-hydroxylation using rabbit liver microsomes in vitro. J Steroid Biochem 1984;21:777-80.

11. Iskandarsyah I, Alvina WP, Ernysagita E. Penetration test of caffein in ethosome and desmosome gel using an in vitro method. Int J Appl Pharm 2017;9:1.

12. Rajan R, Vasudevan DT. Effect of permeation enhancers on the penetration mechanism of transfersomal gel of ketoconazole. J Adv Pharm Technol Res 2012;3:112-6.

13. Anggraini W, Erny S, Iskandarsyah I. Effect of hifrophilicity surfactant toward characterization and in vitro transfersomes penetration in gel using Franz diffusion test. Int J Appl Pharm 2017;9:1.

14. Reza MI, Divya G, Rahul KG, Musarrat HW. Formulation of ketoconazole loaded nano dispersive gel using swollen micelles technique and its in vitro characterization. Int $\mathrm{J}$ Pharm Pharm Sci 2018;10:162-6.

15. Nurleli N, Iskandarsyah I, Ahmad A. Formulation and penetration testing of ethosome azelaic acid on abdomen skin white rats (Rattus norvegicus) with Franz diffusion cell. Int Pharm Clin Res 2018;11:327-30. 